\title{
S-2
}

\section{The pharmacology of sildenafil, a novel and selective inhibitor of phosphodiesterase (PDE) type 5}

\author{
R.M. Wallis \\ Pfizer Central Research, Sandwich, Kent, UK
}

\section{Introduction}

Erectile dysfunction has been described as the persistent inability to achieve and/or maintain an erection sufficient for satisfactory sexual activity ${ }^{1}$. According to the Massachusetts Male Aging Study, erectile dysfunction may affect up to 18 million American men 40 to 70 years old ${ }^{2}$ and should be considered a major health concern. In addition to age, important risk factors for erectile dysfunction include heart disease, hypertension, diabetes, cigarette smoking, spinal cord injury and surgery of the pelvic region.

Penile erection is a haemodynamic response. Increased blood flow into the trabecular spaces of the corpora cavernosa occurs as a consequence of the relaxation of the corpus cavernosum and associated arteries ${ }^{3}$. There is increasing evidence that nitric oxide (NO) has a key role in mediating penile erection. Following sexual stimulation, NO is released from non-adrenergic, non-cholinergic nerves within the penis to activate guanylate cyclase.

Following stimulation of guanylate cyclase the formation of cyclic guanosine monophosphate (cGMP) is increased mediating a relaxation of the corpus cavernosum and penile arterioles ${ }^{4}$. Intracellular levels of cGMP are controlled by a balance between its formation and degradation via cyclic nucleotide phosphodiesterase (PDE) isozymes. Phosphodiesterase type 5 (PDE5) is the pre-dominant isozyme responsible for the metabolism of cGMP in the corpus cavernosum ${ }^{5}$. Thus, inhibition of this enzyme represents a new target for the treatment of erectile dysfunction.

Sildenafil (Figure 1) is a novel inhibitor of PDE5 which has been shown to be an effective oral treatment of erectile dysfunction. This paper describes the pre-clinical pharmacology of sildenafil.<smiles>CCCC(=NC)c1nc(-c2cc(S(=O)(=O)N3CCN(C)CC3)ccc2OCC)[nH]c(=O)c1NC</smiles>

\section{Figure 1 Structure of sildenafil}

\section{In vitro Profile}

Sildenafil potently inhibited PDE5 expressed in the corpus cavernosum (Table 1) and it was selective over PDE1 (80-fold), PDE2 (>19,000-fold), PDE3 (>4,600-fold), PDE4 (2,000-fold) and PDE6 (10-fold). The inhibition of PDE5 by sildenafil has been shown to be competitive in nature ${ }^{6}$. As a consequence of the inhibition of PDE5, sildenafil increased the levels of cGMP in the rabbit corpus cavernosum ${ }^{7}$ and cultured human corpus cavernosum smooth muscle cells ${ }^{8}$. 
Table 1 Effects of sildenafil on the activities of human phosphodiesterase isoenzymes $(n=3-15)$.

\begin{tabular}{|llc|}
\hline PDE isoenzyme & Source & $\begin{array}{c}\text { Geometric mean } \text { IC }_{50} \text { value with } 95 \% \\
\text { Confidence Interval. }\end{array}$ \\
\hline PDE1 & cardiac ventricle & $280.0 \mathrm{nM}(229-337)$ \\
PDE2 & corpus cavernosum & $68.0 \mu \mathrm{M}(31.6-146.3)$ \\
PDE3 & corpus cavernosum & $16.2 \mu \mathrm{M}(9.5-27.8)$ \\
& platelet & $41.2 \mu \mathrm{M}(26.1-65.0)$ \\
PDE4 & skeletal muscle & $7.2 \mu \mathrm{M}(4.5-11.5)$ \\
PDE5 & corpus cavernosum & $3.5 \mathrm{nM}(2.5-4.8)$ \\
& platelet & $6.1 \mathrm{nM}(3.0-12.6)$ \\
PDE6 & retina - cone & $34.1 \mathrm{nM}(24.5-47.4)$ \\
& retina - rod & $37.5 \mathrm{nM}(29.0-48.5)$ \\
\hline
\end{tabular}

In the absence of NO-drive sildenafil had no effect on phenylephrine-contracted rabbit corpus cavernosum. However, it enhanced the relaxant effect of sodium nitroprusside. Thus, the concentrations of sodium nitroprusside which relaxed the rabbit corpus cavernosum was reduced from $6.15 \mu \mathrm{M}$ in the absence of sildenafil to $4.94 \mu \mathrm{M}$ in the presence of sildenafil $10 \mathrm{nM}$. Higher concentrations of sildenafil caused a further potentiation of sodium nitroprusside (Table 2). These data demonstrate that sildenafil acts to potentiate the effects on NO drive in the corpus cavernosum.

Table 2 The effects of sildenafil on the relaxation of phenylephrine $(10 \mu \mathrm{M})$-contracted rabbit isolated corpus cavernosal strips induced by sodium nitroprusside (SNP). Results are mean $\left(95 \%\right.$ Confidence Interval) $\mathrm{IC}_{50}$ s for SNP $(\mu \mathrm{M})(\mathrm{n}=7-10)$.

\begin{tabular}{|lcll|}
\hline $\begin{array}{l}\text { Time-matched } \\
\text { control }\end{array}$ & Sildenafil & \\
Pre-treatment & $6.35(3.41-11.83)$ & Pre-treatment & $6.15(3.04-12.46)$ \\
control 1 & $12.36(7.46-20.47)$ & $10 \mathrm{nM}$ & $4.94(3.24-7.53)^{* *}$ \\
control 2 & $10.39(6.34-17.04)$ & $100 \mathrm{nM}$ & $1.07(0.74-1.56)^{* * *}$ \\
control 3 & $9.77(6.16-15.50)$ & $1000 \mathrm{nM}$ & $0.77(0.44-1.36)^{* * *}$ \\
\hline
\end{tabular}

Significance of difference from time-matched control $\quad{ }^{* *} \mathrm{P}<0.01,{ }^{* * *} \mathrm{P}<0.001$

(Analysis of Covariance adjusted for pre-treatment values)

The ability of sildenafil to potentiate the effects of NO is also observed in other tissues, such as isolated vascular preparations. Consistent with that observed on the rabbit corpus cavernosum, in the absence of NO-drive, sildenafil had no effect on phenylephrine-induced contractions of the rabbit aorta. However, a combination of sildenafil and glyceryl trinitrate increased the concentration of phenylephrine required to contract the rabbit aorta by $50 \%$ of the maximum response from $0.33 \mu \mathrm{M}$ to $6.85 \mu \mathrm{M}$ (Table 3). Therefore sildenafil will potentiate the effects of NO on vascular beds other than the corpus cavernosum.

Table 3 Effects of sildenafil and glyceryl trinitrate (GTN) alone and in combination on the contractile responses of rabbit isolated aortic rings to phenylephrine. $(n=8)$.

\begin{tabular}{|lc|}
\hline \multicolumn{1}{|c|}{ Treatment and concentration } & $\begin{array}{c}\text { Geometric mean }(95 \% \mathrm{C} \text { I }) \\
\mathrm{EC}_{50} \text { for phenylephrine }(\mu \mathrm{M})\end{array}$ \\
Vehicle & $0.33(0.20-0.52)$ \\
GTN $1 \mu \mathrm{M}$ & $1.65(1.05-2.59)$ \\
Sildenafil $1 \mu \mathrm{M}$ & $0.45(0.28-0.70)$ \\
Sildenafil + GTN & $6.85(4.33-10.84)$ \\
\hline
\end{tabular}


PDE3 inhibitors, such as milrinone, have been shown to have vasodilator and positive inotropic effects. The very weak effect of sildenafil on PDE3 would suggest that it should have little or no effect on isolated cardiac tissue. To investigate this further, the effects of sildenafil, in comparison with milrinone, on the isolated dog trabeculae carneae has been studied. Milrinone-induced a concentration related increase in contractility of the electrically stimulated (1 $\mathrm{Hz}, 2-5 \mathrm{msec}$, voltage $10 \%$ above threshold) dog isolated trabeculae carneae (Table 4). In contrast, sildenafil had no effect even at concentrations 1000 -fold higher than those active on the rabbit isolated corpus cavernosum. Thus sildenafil is devoid of direct inotropic effects on isolated cardiac tissue.

Table 4 Effects of sildenafil and milrinone on the contractility of electrically stimulated dog isolated trabeculae. $(\mathrm{n}=7)$.

\begin{tabular}{|lcccc|}
\hline $\begin{array}{c}\text { Concentration }(\mu \mathrm{M}) \\
\text { or equivalent volume } \\
\text { of vehicle }\end{array}$ & Vehicle & Sildenafil & Vehicle & Milrinone \\
\hline 0.01 & $-4.35 \pm 1.88$ & $-1.66 \pm 1.11$ & & \\
0.03 & $-6.92 \pm 1.74$ & $-5.69 \pm 2.97$ & & \\
0.1 & $-11.25 \pm 3.3$ & $-8.93 \pm 3.38$ & $-3.42 \pm 1.43$ & $+1.01 \pm 1.01$ \\
0.3 & $-11.25 \pm 3.30$ & $-9.73 \pm 3.10$ & $-5.90 \pm 2.82$ & $+5.40 \pm 3.96$ \\
1 & $-11.55 \pm 3.28$ & $-10.89 \pm 3.58$ & $-7.56 \pm 2.41$ & $+13.76 \pm 6.32$ \\
3 & $-12.35 \pm 2.96$ & $-11.54 \pm 3.98$ & $-11.32 \pm 4.62$ & $+24.43 \pm 9.99$ \\
10 & $-13.15 \pm 2.69$ & $-14.26 \pm 3.93$ & $-12.16 \pm 4.56$ & $+38.36 \pm 12.00$ \\
30 & & & $-14.66 \pm 6.56$ & $+46.00 \pm 13.54$ \\
60 & & & $-15.50 \pm 6.55$ & $+61.40 \pm 15.71$ \\
\hline
\end{tabular}

Results are the mean, \pm S.E.M., percentages of the maximum response induced by isoprenaline

\section{In vivo Profile}

An injection of sodium nitroprusside in to the corpus cavernosum of the anaesthetised dog induced a small rise in intracavernosal pressure (Figure 2). Intravenously administered sildenafil had no effect on intracavernosal pressure when given alone, but potentiated, in a dose-related manner $\left(\mathrm{ED}_{50} 16.2 \mu \mathrm{g} / \mathrm{Kg}\right)$, the effects of sodium nitroprusside. These effects were observed in the absence of meaningful effects on blood pressure. A similar effect of sildenafil on changes in intracavernosal pressure induced by stimulation of the pelvic nerve has also been demonstrated in the $\operatorname{dog}^{9}$. The plasma concentrations of free drug achieved in these studies following efficacious doses of sildenafil were approximately $2 \mathrm{nM}^{9}$.

Figure 2 A representative figure showing the effects on intracavernosal pressure of sodium nitroprusside (SNP) injected into the corpus cavernosum either alone (control) or following intravenous doses of sildenafil in the anaesthetised dog.

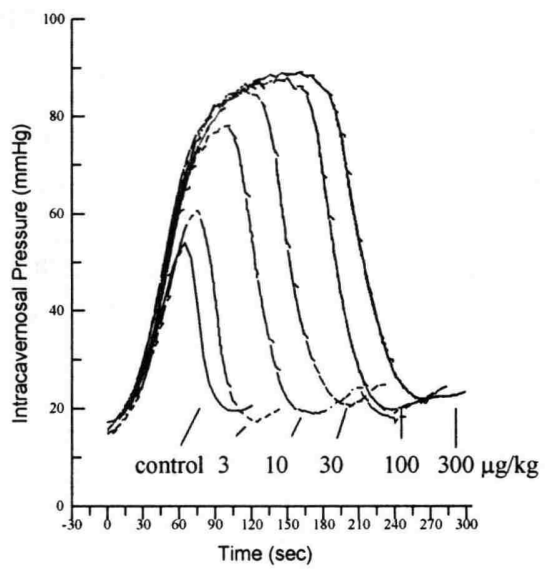


PDE6 is expressed in the retina and has an important role in phototransduction. Thus, upon absorption of light, rhodopsin, the visual pigment of the rod, stimulates PDE6 via the G-protein, transducin ${ }^{10}$. The consequent increase in hydrolysis decreases the concentration of cGMP, leading to closure of the cGMP-gated ion channel and hyperpolarisation of the photoreceptors. The characteristic changes in electrical potential in the retina can be measured via surface corneal electrodes in the form of the electroretinogram which consists of several electrical potentials of known origin ${ }^{11}$. The photoreceptors (rods and cones) hyperpolarise in response to light giving rise to the initial negative, a-wave, of the ERG. The positive b-wave reflects the subsequent depolarisation of the postsynaptic Müller and bipolar cells. The effects of intravenously-administered sildenafil on the ERG response to a flash of blue light was studied in the dark-adapted anaesthetised dog. Plasma concentrations of sildenafil which were efficacious on the corpus cavernosum had no effect on the ERG (Figure 3). Higher concentrations (100 to $1000 \mathrm{nM}$ ) caused a dose-related increase in the implicit time of the a-wave and b-wave and reduction in the amplitude of the awave of the ERG. These effects were fully reversible and returned to pre-treatment values in a manner consistent with the plasma half life in the dog. Importantly, in long term toxicology studies, there was no change in the structure of the retina of animals exposed to these concentrations of sildenafil which were active on the ERG ${ }^{12}$. The ability of high doses of sildenafil to modify the ERG response to a flash of light is consistent with inhibition of PDE6 and probably accounts for the low incidence of visual adverse events observed in clinical trials with sildenafil.

Figure 3 A representative figure to show the effects of intravenously-administered sildenafil on the electroretinogram (ERG) of the dark-adapted anaesthetised dog evoked by a flash ( $50 \mathrm{mcsec})$ of blue light.

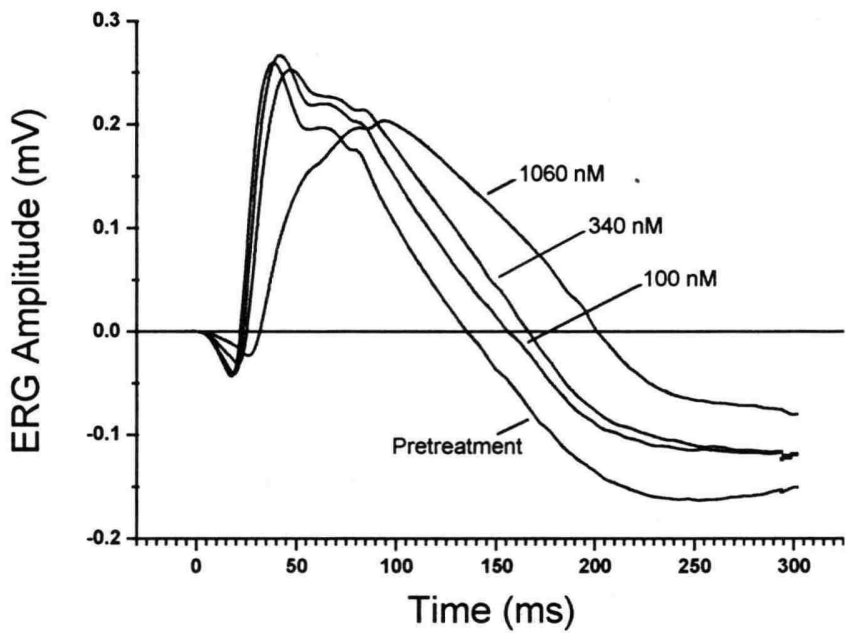

\section{Conclusions}

In conclusion, sildenafil has been shown to be a potent and selective inhibitor of PDE5. Although the compound has little direct effect on the corpus cavernosum it potently enhanced the relaxant effects of nitric oxide both in vitro and in vivo. The selectivity of sildenafil over key phosphodiesterase enzymes has also been confirmed in functional tests. Thus, sildenafil had no effect on the dog trabeculae carneae and therefore has no direct inotropic effect. Furthermore, the functional selectivity of sildenafil for PDE5 compared with PDE6 has also confirmed in the anaesthetised dog. Plasma concentrations which were active on the corpus cavernosum had no effect on the ERG evoked by a flash of blue light in the dog. These data suggest that the low incidence of visual adverse events observed with high doses of sildenafil in patients with erectile dysfunction are mediated through inhibition of PDE6.

Overall, the pre-clinical pharmacology of sildenafil has confirmed that the compound is a potent and selective PDE5 inhibitor useful in the treatment of erectile dysfunction. 


\section{References}

1) National Institutes of Health consensus development panel on impotence. Impotence. JAMA 270, 83-90 (1993)

2) Feldman HA, Goldstein I, Hatzichristou DG, Krane RJ and McKinlay JB: Impotence and its medical and psychosocial correlates:results of the Massachusetts male aging study. J. Urol. 151, 54-61 (1994)

3) Andersson K-E and Wagner G: Physiology of penile erection. Physiol. Rev. 75, 191-236 (1995)

4) Trigo-Rocha F, Hsu GL, Donatucci CF and Lue TF: The role of adenosine monophosphate, cyclic guanosine monophosphate, endothelium and nonadrenergic, noncholinergic, neurotransmission in canine penile erection. J. Urol. 149, 872-877 (1993)

5) Boolell M, Allen MJ, Ballard SA, Gepi-Attee S, Muirhead GJ, Naylor AM, Osterloh IH and Gingell C: Sildenafil: an orally active type 5 cyclic GMP-specific phosphodiesterase inhibitor for the treatment of penile erectile dysfunction. Int. J. Impotence Res. 8, 47-52 (1996)

6) Ballard SA, Gingell CJ, Tang K, Turner LA, Price ME and Naylor AM: Effects of sildenafil on the relaxation of human corpus cavernosum tissue in vitro and on the activities of cyclic nucleotide phosphodiesterase isozymes. J. Urol. 159, 2164-2171 (1998)

7) Jeremy JY, Ballard SA, Naylor AM, Miller MAW and Angelini GD: Effects of sildenafil, a type-5 cGMP phosphodiesterase inhibitor, and papaverine on cyclic GMP and cyclic AMP levels in the rabbit corpus cavernosum in vitro. Brit. J. Urol. 79, 958-963 (1997)

8) Moreland RB, Goldstein I and Traish A: Sildenafil, a novel inhibitor of phosphodiesterase type 5 in human corpus cavernosum smooth muscle cells. Life Sci. 62, 309-318 (1998)

9) Carter AJ, Ballard SA and Naylor AM: Effect of the selective phosphodiesterase type 5 inhibitor sildenafil, on erectile function in the anaesthetized dog. J. Urol. 160, 242-246 (1998)

10) Hurwitz RL, Bunt-Milam AH, Chang, ML and Beavo JA: cGMP phosphodiesterase in rod and cone outer segments of the retina. J. Biol. Chem. 260, 568-73 (1985)

11) Ikeda H. Retinal mechanisms and the clinical electroretinogram: In: Halliday AM, Butler SR and Paul R, eds. Textbook of Clinical Neurophysiology 22, 569-94 (1987)

12) Wallis RM, Leishman D, Pullman L, Graepel $P$ and Heywood R: Effects of sildenafil on retinal histopathology and electroretinogram (ERG) in dogs. Ophth. Res. 30 (S1), 68 (1998).

Abstract - The pharmacology of sildenafil, a novel and selective inhibitor of phosphodiesterase (PDE) type 5. R.M. Wallis, Pfizer Central Research, Sandwich, Kent, UK.

Folia Pharmacol. Jpn. (Nippon Yakurigaku Zasshi) 114, Suppl 1, 22P 26P (1999)

Sildenafil (1-[4-ethoxy-3-(6,7-dihydro-1-methyl-7-oxo-3-propyl-1H-pyrazolo [4,3-d]pyrimidin-5-yl) phenylsulphonyl]-4-methylpiperazine) has been shown to be an effective oral treatment for male erectile dysfunction. Sildenafil is a potent competitive inhibitor of PDE5 (IC $503.5 \mathrm{nM}$ ) and is selective over PDE1 to 4 ( 80 to 19,000fold) and retinal PDE6 (10-fold). Sildenafil enhanced cGMP accumulation driven with sodium nitroprusside in the corpus cavernosum of rabbits without affecting cAMP formulation. In the absence of nitric oxide drive, sildenafil had no functional effect on the human and rabbit isolated corpus cavernosum, but potently potentiated the relaxant effects of nitric oxide on these tissues. In the anaesthetised dog, sildenafil $\left(\mathrm{ED}_{50}: 12\right.$ to $16 \mu \mathrm{g} / \mathrm{kg}$ i.v.) enhanced the increase in intracavernosal pressure induced by electrical stimulation of the pelvic nerve or intracavernosal injection of sodium nitroprusside in the absence of meaningful effects on blood pressure. Consistent with its mode of action, sildenafil potentiated the vasorelaxant effects of glyceryl trinitrate on rabbit isolated aortic rings. However, unlike milrinone, sildenafil had no inotropic effects on the dog isolated trabeculae carneae. Thus it is unlikely to have the deleterious effects on cardiac function associated with PDE3 inhibitors. As a consequence of inhibition of PDE6 in the retina, sildenafil $(1$ to $100 \mu \mathrm{M})$ altered the kinetics of the light response of the dog isolated retina. In the anaesthetised dog, sildenafil modified the a- and b-wave of the electroretinogram induced by a flash of blue light. These effects were proportional to plasma concentrations, were fully reversible and only occurred following plasma concentrations higher (approximately 30 -fold) than those active on intracavernosal pressure. These studies have shown that sildenafil is a potent and selective inhibitor of PDE5. It enhances the effect of nitric oxide on the corpus cavernosum and has been shown to be an effective oral treatment of erectile dysfunction.

Key Words: sildenafil, PDE5 inhibitor, pharmacology, in vitro, in vivo 